\title{
CONSERVATION AFTER EARTHQUAKE OF MINIMAL URBAN FRAMEWORK HISTORICAL HERITAGE
}

\author{
S. D'Avino 1, * \\ ${ }^{1}$ Department of Architecture University of Pescara, Italy - sdavino@unich.it
}

Commission II - WG II/8

KEY WORDS: Earthquake, Reconstruction, Surrounding Landscape, Identity

\begin{abstract}
:
Three years after the earthquake that struck central Italy, a number of pressing points need to be addressed as part of a far-ranging discussion that seeks to identify the steps to be taken in response, including: the widespread agreement on the need for reconstruction efforts which ensure a high level of security; the importance of preserving the urban fabric of 'minimal' population centres that are unquestionably intertwined with their surrounding landscapes; the need to acknowledge the most valuable features of historic downtown areas, including their undeniable fact of their intrinsic fragility in the face of seismic events, even though construction techniques developed and refined over time have provided them with a certain resilience. While use is made of a frankly contemporary idiom, when needed to remedy shortcomings, a reconstruction grounded in a critical understanding of the 'sense of place' must guarantee that the identifying features of historic downtown areas remain in place (at least in terms of the lay of the land and spatial relations) while, at the same time, ensuring that the constantly evolving memories which render such areas unique are also preserved, so as to allow the past to play its rightful role in the planning of the future.
\end{abstract}

\section{INTRODUCTION}

The rebuilding of 'minor' historical constructed assets affected by earthquakes raises an unavoidable underlying issue: namely the antinomy between restoring what has been lost and preserving the original nature of the constructed fabric and the urban layout. While safety always constitutes the fundamental consideration when drawing up procedures of post-seismic intervention, the need to preserve the historic memory of urban centres, meaning the most representative expression of their cultural heritage, is also a concern of critical importance, to be addressed without delay.

The damage done by an earthquake, which rips apart not only architectonic constructs, but the very awareness and identity of the resident population, must be repaired forthwith, at the same time as steps are taken to rebuild ample portions of a delicate historical fabric characterised by a readily apparent integration with the surrounding landscape: a unity between the architecture and its setting, outlined by a memory that has stratified in the course of centuries, only for a portion to be completely lost. Though a similar undertaking may draw on methodologies of proven effectiveness, it must also take into consideration the unique nature of each piece of material evidence of the past, all of which, therefore, should receive specific attention and 'care'.

This process is characterised by the fact that, as Giovanni Carbonara aptly notes, "... it calls for an ability to summarise and understand that can only come from lengthy experience, plus a solid technical and scholarly background" (Carbonara 1997 , p. 135). The first step is to gather thorough documentation on all the construction techniques and criteria implemented over the centuries to prevent earthquake damage, so as to gain an understanding of the resistance of different materials, plus the greater or lesser degree to which a given structural mechanism adapts to seismic events. This research and analysis were codified, for that matter, in a number of treatises and manuals, with the focus shifting over time from the materials used, to the construction activities carried out, viewed as a language that gradually adapted itself, in response to the knowledge gained over the centuries.

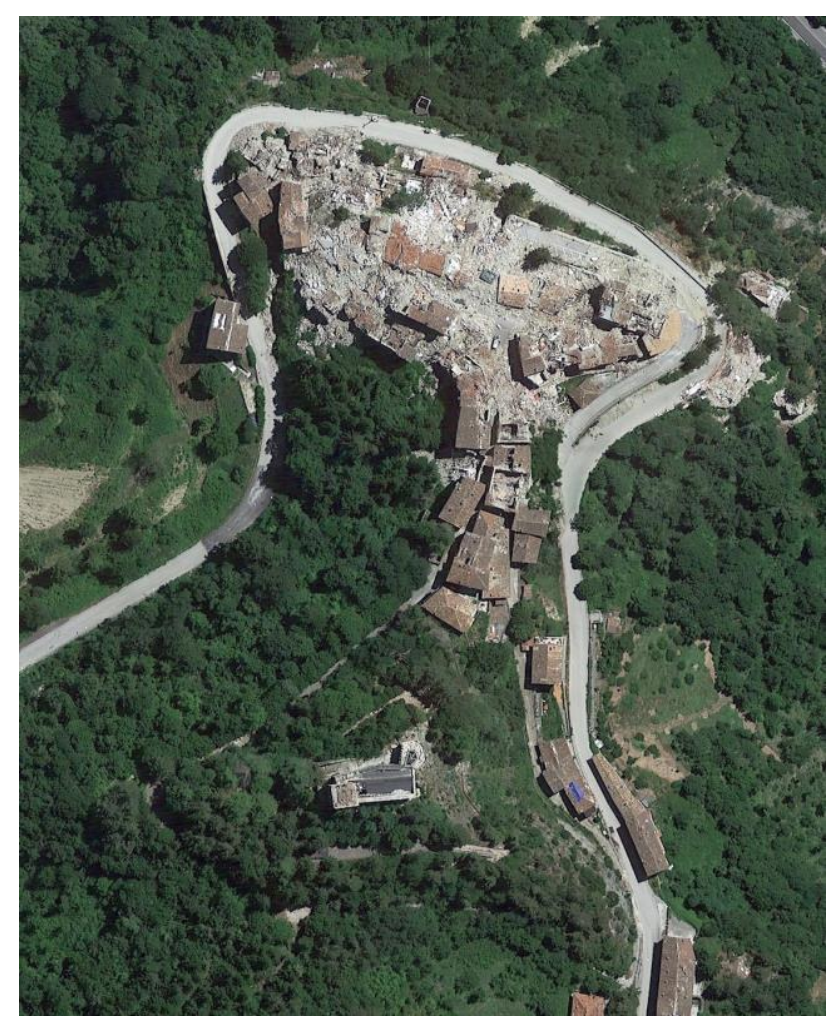

Figure 1. Arquata del Tronto (Ascoli Piceno), aerial view.

\footnotetext{
* Corresponding author
} 
The role of experience, fully appreciated by Kant (Von den Ursachen der Erdersschutterungen, 1726), contributed to identification of the technical features best suited to improve the resistance of structures and, more generally, of the anti-seismic safeguards which can be found even in the oldest examples of architecture, though there is no evidence that they were recognised as distinct practices within the overall technical culture of the times, and yet anti-seismic features such as buttresses, chains, stays and grips reinforcing masonry eventually became an integral part of construction rules.

\section{METHODOLOGY}

Given the precise correlation between the manner in which damage manifests itself and the construction technique characterising a masonry structure, the research must be based on prior knowledge of the buildings and their history, as well as an analysis of the morphology of the sections of the walls, plus observation of the damage mechanisms suffered and the extent to which the steps and measures taken in the past proved effective. Knowledge of traditional building will be important in determining what should be done in the future, prior to catastrophic events, to ensure that historic constructions avoid damage, while seeing to it that they are preserved.

The development of what are known as the 'rules of craftsmanship' is nothing more than the gradual refinement over time, through the construction of historic buildings, of the working criteria and principles of geometric proportion for the constructions: criteria and principles that, depending on the materials available, combined to form construction techniques which included specific local features.

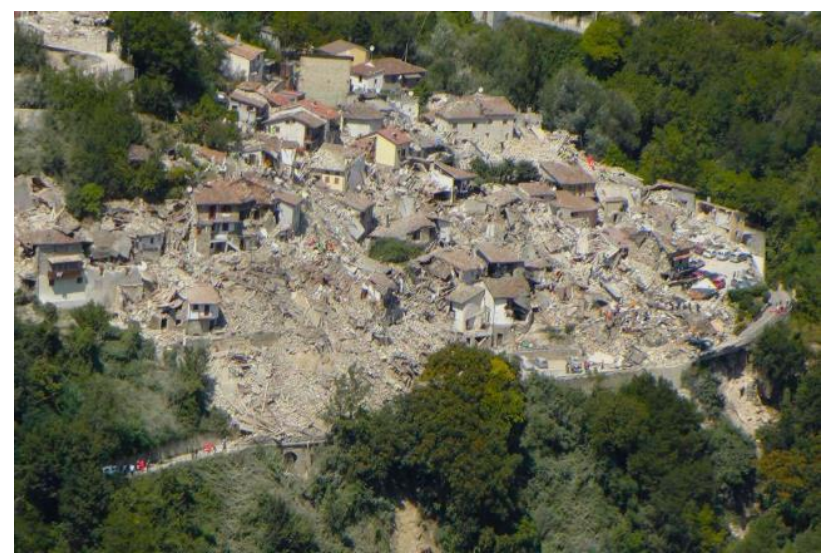

Figure 2. Accumoli (Ascoli Piceno) after 2016 earthquake.

All this without forgetting that the relationship between architecture and memory extends well beyond the realm of mere historical investigation, as shown by the unquestionable individuality of the structural mechanisms that characterise any example of architecture, seeing that their behaviour, more often than not, lacks any systematic structural framework, due in part to prior restoration efforts, and so they cannot be looked upon as 'models'. In terms of urban memory, an effort should be made to favour a process of rebuilding based primarily on repairing, salvaging and restoring what has survived the earthquake, even if it is no more than the urban layout (town squares, street patterns, types of homes etc.), while avoiding approaches that call for complete demolition and subsequent reconstruction, with the attendant risk of losing elements that mark the identity of the sites in question.
How to proceed? The conceptual evolution of recent decades has led to the formulation of a number of different operating strategies, ranging from a philological approach to restoration based on the reiterated application of a traditional linguistic code to the practice of a planning function limited through critical feedback. "Should what is missing involve a significant portion of a whole (...) and assuming that the missing elements "do not constitute a monument in and of themselves (...) then, although they are not constructed works, they nevertheless provide spatial information, but precisely because they are not constructed works, they do not diminish the artistic quality of the environment, in which they are inserted only as generically qualified spatial limits (...), and so the missing elements may be reconstructed to recreate the original spatial array that was lost" (Brandi, 1963, p. 61).

Consideration must be given to the expressive quality of the existing structures from earlier ages, heeding the suggestions gathered from an attentive examination of their attributes in terms of materials and form, so as to establish a harmony with them. Restructuring work must respect the balance reached by the architecture through the use of an idiom that proves 'distinctive', though also well attuned aesthetically to what exists, with the addition always playing a secondary role and not undermining the figurative unity it is meant to restore.

It is best to maintain, during a restoration effort, both the motifs of the historical documentation and the memory of the event: an initiative grounded in an historical analysis, even if it includes partial reconstructions, in no way lessens the impact of the monument's memory.

The practice of restoration must consider this approach; in contrast to "a conservative outlook on preservation, we must adopt a vision of active memory, of imaginative memory" (Cacciari, 2000, p. 13).

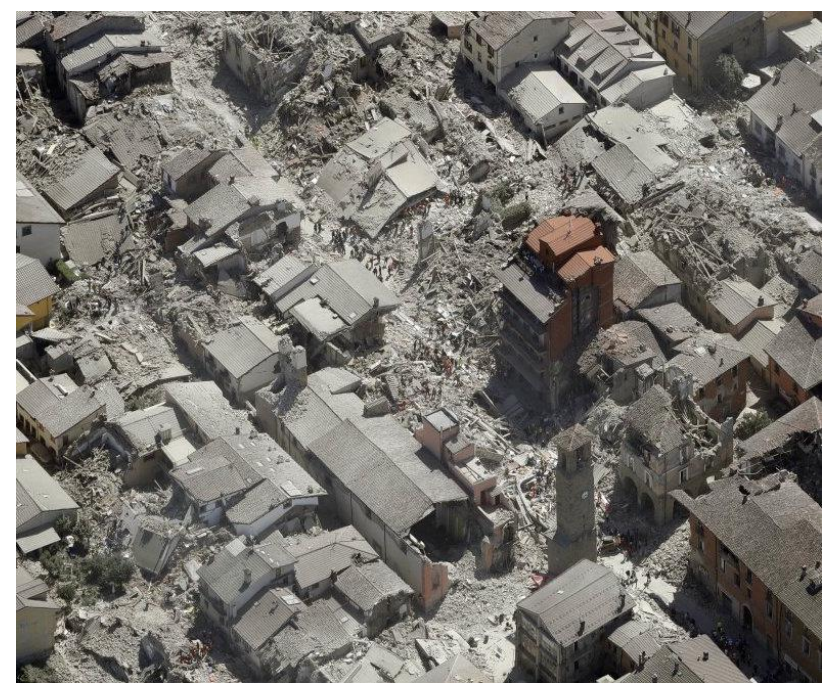

Figure 3. Amatrice (Rieti) after 2016 earthquake.

As stated by Maurice Halbwachs, "Memories intermingle with each other in the image of a place" (Halbwachs, 2001, p. 27): on the walls of the homes damaged by the seism, the narration of both the structures and the events become an illustration of a past that is increasingly close at hand.

The issue of rebuilding what is missing places the focus on the relationship between the old, existing structures and the modern 
inserts. A restoration must establish a fruitful relationship with the remains by facilitating their reformulation and utilising modern materials, under the principle of least possible intervention, rather than constructing an irreversible addition. In essence, the plans for what is new must involve the old in a manner that proves vitally alive, setting in motion a process geared towards restoring identity, in a positive historical contamination, all in the interests of arriving at a sensible and 'historically aware' reinterpretation of the genius loci. In contrast, a distorted, dissonant idiom would hinder integration of the fragmented portion, setting up a contrast between new and old, with the trappings of the contemporary project overlaid on the idiom of old, so that the restoration appears to be nothing but a pretext.

In June of 1981, shortly after the seismic event that did noteworthy damage to the Irpinia region on 23 November 1980 , and two years following the earthquake that struck Valnerina in September of 1979, Tomas Maldonado, editor of the 'Casabella' magazine, wrote an editorial entitled Terremoto, quale ricostruzione (The Earthquake, How to Rebuild). The author did not use a question mark, as if to emphasise the eminently technical capacity to manage the reconstruction process, though this aptitude, at least in the practical sphere, has yet to manifest itself, leading instead, in the intervening years, to in-depth critical reflections.Apart from obviously indispensable emergency work to resolve the housing problems of the moment and to ensure the safety of the damaged portions of the historical architectural heritage, discussions of reconstruction should be held within the framework of a cultural policy geared towards addressing seismic risk and the resulting strategies, with the ultimate goal of safeguarding the historic-architectonic heritage, though naturally without neglecting the all-important tie between defence of the historical heritage and the upgrading of urban centres to reflect the changed (and still changing) living conditions of today's multifaceted society.

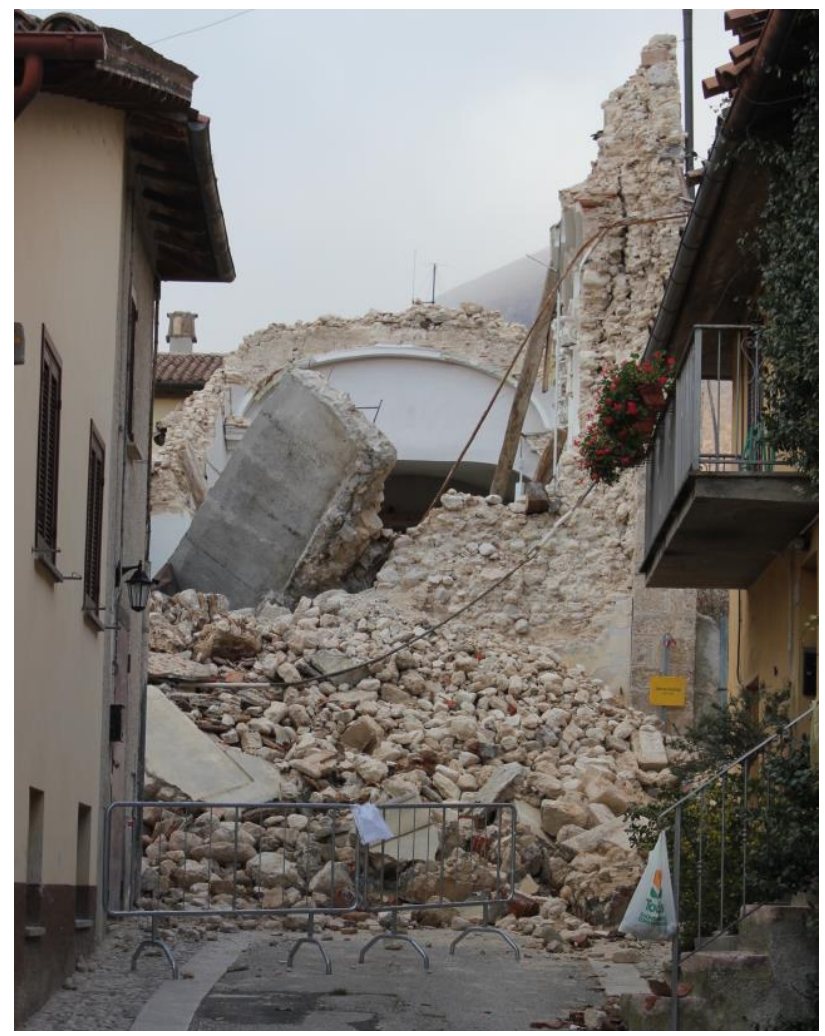

Figure 4. Norcia (Perugia). The collapse of the Crucifix church.
So rather than ask 'how' to preserve, it might be better to raise the question of 'whether to preserve', followed by 'what to preserve'?

The earthquake has occasioned a reconsideration of an issue that had long seemed settled: should everything be rebuilt as it was and where it was after a seismic event?

This approach is definitely alluring, though it still contains room for ambiguity. In particular, the concept of 'as it was' can be applied in a number of different ways, from what is known as a 'philological' reconstruction to a restoration of the outside appearance, with the external features preserved but changes in the interior settings, even if this is done at the expense of features of type and construction that nevertheless constitute an integral part of the architecture.

It would be better to rebuild with an eye towards preserving as much as possible of the remains of the old materials, acting in a fully-informed manner attuned to a culture of planning. Other situations may call for a new, respectful melding of the old and new, while still others may involve buildings that, though modern, embody memories of urban features, plus the volumes, spaces, structural features, materials and colours of old.

The topic of preserving the historic cores of minor population centres affected by earthquakes also raises perplexing questions on the geological insecurity of the stricken zones, as well as the exodus of their populations (already underway for a number of decades, in an apparently irreversible trend).

There is no question, therefore, that any restoration project must be approached on a number of different levels: individual buildings, the urban settlement as a whole, the countryside; while the plans for the reconstruction of historic urban cores should be inspired by an historic-evolutionary analysis of the town, focussing on determining the processes that led to the formation of the urban fabric and its constructions while studying their effect on the material components of constructed elements, in order to prevent damage from seismic events. And so the goal is to see to it that historical knowledge of the mechanisms of a town's development plays an increasingly active role in preservation efforts.

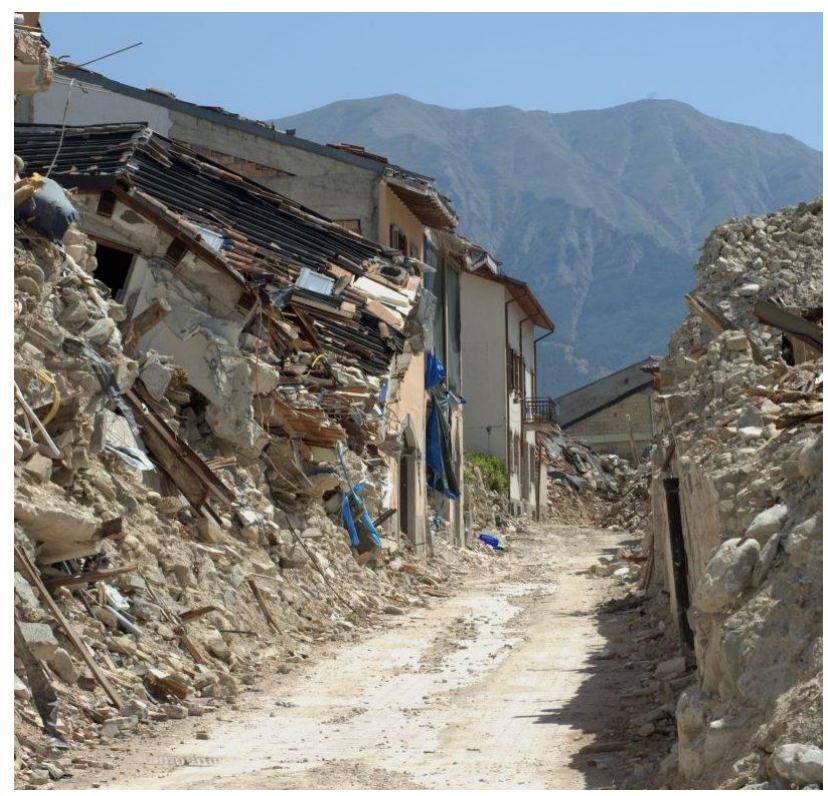

Figure 5. Amatrice. The historic center after the earthquake. 
The extension of the concept of the monument to different settings and dimensions raises new issues of criticism and interpretation involving the 'sense of place', and so suitable tools of intervention tied to the discipline of urban development and to the methodologies of territorial planning should be introduced for use alongside those of restoration.

Precisely because the primary objective is preserving the meaning of a place, the initiatives should not modify the preexisting layouts of roadways or plots of land, meaning the most authentic evidence of the initial manmade structures. In fact, the relationship that the town establishes with its surrounding context influences and moulds its entire structure, from the array of its roads and paths to blocks of houses, as well as the layout of its homes and spaces for social relations.

Though portions of the urban fabric which, once the extent of the damage has been diagnosed, are only marginally affected must be faithfully preserved, it is not unfeasible to postulate a reconstruction process that considers what amounts to a 'thinning out' of portions of the fabric that could increase seismic risk, an approach that would make possible exceptions (tending towards the contemporary) in the architectonic idiom while, at the same time, preserving the features that determine the identity of the urban structure, plus specific instances of reciprocity between the constructed and the connecting fabrics. A town should be viewed, therefore, as the product of a series of processes, a sequence of modifications over a lengthy timeframe, all of them contributing, in indistinguishable ways, to the authenticity and the development of the identity of the places, forming not a 'sum total', but an 'entirety'.

Critical comprehension must be extended to include the sense of place, attempting to identify the architectonic vocation, the connections with the surroundings and the spatial relations with the environment, all of which, rather than falling under a geometric, mathematical or otherwise rational conception of space, prove more intuitive and emotionally incisive, with the result that the post-seismic reconstruction becomes a question having to do (primarily) with the countryside.

Attention should be extended to wider-ranging settings, ties should be established with urban development and planning, but with the focus on assimilating the most expressive figurative and spatial features, so as to arrive at a more accurate formal control of the entire initiative. Safeguarding the original urban layout does not necessarily entail a total absence of planning, seeing that planning, in actual fact, influences the preservation of the 'contextual' urban characteristics, albeit within a framework of ongoing change and evolution, as per the criteria of 'integrated preservation' already expressed a few decades ago in the Declaration of Amsterdam (1975). In settings that prove so complex, and also weak, an individual urban cell or residential block is never going to spark interest in a renewal effort, but should rather be viewed as part of a whole, of a context, with a more extensive role as "a component element of a language, like a word inside a preposition, which contributes to the meaning of the phrase, but has no significance in and of itself" (Dalla Negra, 2013, p. 46); and as in the case of a language, there must be acceptance of any transformation, recycling or adjustment to changing conditions, and of the different critical-perceptive sensibility inherent to the contemporary age.
The main topic for reflection, as noted, becomes the preservation of the site (or at least the original setting), plus consideration of the layers of development that have gradually accumulated within the context: what Lewis Mumford refers to as "soul of the town" (Mumford, 2002, p. 44).

The reconstruction process must be based on the recovery and restoration of what was saved from the earthquake, including remains at the level of the urban layout alone (town squares, street patterns, types of homes etc.); in any event, a boundary as precise as it is solid.

\section{CONCLUSIONS}

In the specific case of minimal urban structures (settled centres often characterised by a clearly historical context and a distinctive morphology of routes and geometries that have diversified and become stratified over the centuries), it is of fundamental importance that the original site be preserved, though naturally without forgetting that full preservation of the ruins alone could lead, long-term, to their gradual abandonment, due to the inability of the new settlement to reprise the original factors of identity.

"In the case of the earthquake that struck the northeast portion of Umbria in September of 1979, the 'memory of the place' was not allowed to remain, due to support of a disjointed reconstruction that ultimately cancelled history by replacing it, irreversibly altering the context" (D’Avino, 2017, p. 62).

The abandonment of pre-existing systems of settlement, or their reconstruction-shifting, as occurred to a number of urban centres in Umbria following the 1979 earthquake, resulted in the definitive cancellation of any sign of their evolutionary memory, together with a significant portion of the region's technical culture. Especially in the case of settlements found at high altitude (as were the majority of those affected by the 2016 earthquake), under no circumstances would a preservation effort based on an historical selection be acceptable, given that an urban centre, by its very nature, exists as an historical present that undergoes continuous transformation, outside of any time framework, characterised by an historical register tied to the diachronic concept of evolution. This contextual manifestation of history is present in the enduring arrangement of the materials as authentic morphological and spatial systems, remains that narrate the past as if, "history was moulded into the stones" (Rowse, 1977, p. 42).

A concern also shared by Cesare Brandi, who points out that "the disassembly and reconstruction of a monument other than that on which it was built" should not be accepted, being 'illegitimate' less for the historical reasons referred to than out of aesthetic considerations, "in that the alteration of the spatial coordinates of a monument compromises it as a constructed work" (Brandi, 1963, p. 48). Such an approach would give rise to an insurmountable dichotomy between the two urban centres: the old one (where the traces of identity are destined to fade away over time) and the modern one, a product of the application of abstract models detached from history. In the end, the stability of architectonic forms that manage to persist in sites affected by seismic events (from individual housing blocks to the urban structure as a whole, including the layout of routes and paths) will wind up being guaranteed by their proven 'syntactic' suitability to the physical characteristics of the territory in which they are found. 


\section{REFERENCES}

Brandi, C., 1963 (2nd edition Rome, 1972): Teoria del restauro. Edizioni di Storia e Letteratura, Roma.

Cacciari, M., 2000: Relazione introduttiva, Cristinelli G., Foramitti V. (edited by), Il restauro fra identità e autenticità, proceedings of a roundtable held in Venice 31/1-1/2/1999. Venice.

Carbonara, G., 1997: Avvicinamento al restauro, Liguori, Naples.

Dalla Negra, R., 2013: Eventi eccezionali e principi conservativi: il terremoto emiliano, Materiali e strutture, problemi di conservazione, I, pp. 42-53.

D'Avino, S., 2017: Lacune 'programmate'. Il caso di alcuni centri minori in Umbria dopo il terremoto del 1979, R. Dalla Negra, C. Varagnoli (edited by), Le lacune urbane tra presente e futuro, Pescara 4.3.2015, vol. II, pp. 53-64. Città di Castello.

Halbwachs, M., 2001: La memoria collettiva. Milano.

Maldonado, T., 1981: Terremoto, quale ricostruzione, Casabella, 470, June 1981, year XLV, pg. 7.

Mumford, L., 2002: La città nella storia (orig. ed. The City in History, 1961. Roma.

Rowse, A., L., 1977: Heritage of Britain. Artus, Bristol. 